\title{
Connexin Hemichannels Contribute to the Activation of cAMP Signaling Pathway and Renin Production
}

\author{
Jingru Hong and Jian Yao * \\ Division of Molecular Signaling, Department of the Advanced Biomedical Research, \\ Interdisciplinary Graduate School of Medicine, University of Yamanashi, Chuo 409-3898, Japan; \\ lulujane0130@gmail.com \\ * Correspondence: yao@yamanashi.ac.jp; Tel.: +81-55-273-8074
}

Received: 31 May 2020; Accepted: 22 June 2020; Published: 23 June 2020

\begin{abstract}
Connexin hemichannels play an important role in the control of cellular signaling and behaviors. Given that lowering extracellular $\mathrm{Ca}^{2+}$, a condition that activates hemichannels, is a well-characterized stimulator of renin in juxtaglomerular cells, we, therefore, tested a potential implication of hemichannels in the regulation of renin in As4.1 renin-secreting cells. Lowering extracellular $\mathrm{Ca}^{2+}$ induced hemichannel opening, which was associated with cAMP signaling pathway activation and increased renin production. Blockade of hemichannels with inhibitors or downregulation of Cxs with siRNAs abrogated the activation of cAMP pathway and the elevation of renin. Further analysis revealed that cAMP pathway activation was blocked by adenylyl cyclase inhibitor SQ 22536, suggesting an implication of adenyl cyclase. Furthermore, the participation of hemichannels in the activation of the cAMP signaling pathway was also observed in a renal tubular epithelial cell line NRK. Collectively, our results characterized the hemichannel opening as a presently unrecognized molecular event involved in low $\mathrm{Ca}^{2+}$-elicited activation of cAMP pathway and renin production. Our findings thus provide novel mechanistic insights into the low $\mathrm{Ca}^{2+}$-initiated cell responses. Given the importance of cAMP signaling pathway in the control of multiple cellular functions, our findings also highlight the importance of $\mathrm{Cx}$-forming channels in various pathophysiological situations.
\end{abstract}

Keywords: connexin; hemichannel; $\mathrm{Ca}^{2+}$; renin; cAMP; renin-secreting cells

\section{Introduction}

The renin-angiotensin system is a major regulatory system controlling extracellular fluid volume and blood pressure. The rate-limiting enzyme in this hormonal cascade is renin, which is secreted into the circulation by renal juxtaglomerular (JG) cells of the afferent arteriole. Renin secretion is controlled by several factors, such as blood pressure, sodium chloride load, sympathetic nerves, hormones, cytokines, and vasoactive materials. Although the signal pathways underlying the actions of these factors differ, it is generally accepted that a change in intracellular $\mathrm{Ca}^{2+}$ is the common pathway through which renin secretion from JG cells is governed. In contrast to other secretory cells, in which an increase in $\mathrm{Ca}^{2+}$ usually promotes secretion, renin secretion is inversely related to the $\mathrm{Ca}^{2+}$ concentration in JG cells [1-7].

The molecular mechanisms by which $\mathrm{Ca}^{2+}$ regulates renin have been the focus of many previous investigations $[1,2,4,5,8]$. Accumulated evidences indicate that $\mathrm{Ca}^{2+}$ regulates renin through modulation of adenylyl cyclase activities. Low $\mathrm{Ca}^{2+}$ enhances the activities of the $\mathrm{Ca}^{2+}$-inhibitable isoforms of adenylyl cyclases in JG cells, thus increasing intracellular cyclic adenosine monophosphate (cAMP) and stimulating renin synthesis $[1,2,8]$. Oppositely, elevation in intracellular $\mathrm{Ca}^{2+}$ suppresses adenylyl cyclase and inhibits renin [5]. In fact, cAMP is a well-characterized secondary messenger in stimulation 
of renin synthesis and secretion [8-11]. cAMP-elevating chemicals such as prostaglandins, kinins, and alpha-adrenergic agonists, all stimulate renin, whereas agents that inhibit the cAMP pathway suppress renin [11-13].

Gap junctions (GJs) are intercellular channels that permit the direct exchange of ions, secondary messengers, and small signaling molecules among neighboring cells. Each GJ channel is composed of two hemichannels that reside in the plasma membrane of two closely apposed cells. Each hemichannel is composed of six protein subunits termed connexin (Cx). Up to now, more than 20 different $C x$ molecules have been identified. Gap junction-mediated intercellular communication (GJIC) plays an important role in the regulation of cell signaling and functions [14-16]. In the juxtaglomerular apparatus of kidney, GJIC provides a pathway for signal transduction and coordination of multicellular functions. Disruption of cell-to-cell communication in the JGA alters preglomerular vascular tone and renin secretion $[15,17,18]$. Knockout of Cx40 in renin-secreting cells led to increased renin level and renin-dependent hypertension, which was presumably due to dysfunction of gap junction-mediated negative regulatory signals [19-21].

Besides intercellular GJ channels, the non-junctional Cx hemichannels are also activated under various pathophysiological situations and participate in the regulation of cellular behaviors through the release of mediators such as cAMP, adenosine triphosphate (ATP), nicotinamide adenine dinucleotide $\left(\mathrm{NAD}^{+}\right)$, glutamate or prostaglandin E2 (PGE2) [16,22-25]. Several considerations promoted us to speculate a potential implication of hemichannels in the control of renin. First, among the molecules released by hemichannels, some of them are closely related to cAMP signaling pathway such as cAMP, ATP and PGE2 [24-26]. Second, removing extracellular $\mathrm{Ca}^{2+}$, a situation that stimulates renin, also activates hemichannels [9,27-31]. Third, participation of several membrane channels in the regulation of renin has been previously documented [32-34]. Therefore, we designed this study to address the role of hemichannels in low $\mathrm{Ca}^{2+}$-induced activation of cAMP pathway and renin production.

Here, we present our results that hemichannel opening is requisite for the effective activation of the cAMP signaling pathway-induced low $\mathrm{Ca}^{2+}$ in mouse renin-secreting cells. Given the importance of the cAMP signaling pathway in multiple pathophysiological situations, the activation of the pathway by hemichannels provides a novel mechanistic insight into the actions of $\mathrm{Cx}$ hemichannels and suggests that $\mathrm{Cx}$ channels are critically involved in the control of many cellular processes.

\section{Results}

\subsection{Removing Extracellular $\mathrm{Ca}^{2+}$ Activates Hemichannels in As4.1 Cells}

To determine hemichannel activity after removing the extracellular $\mathrm{Ca}^{2+}$, we have used a renin-expressing cell line As4.1. This cell line was isolated from a mouse renal tumor and has been well characterized for the synthesis, storage and secretion of renin. We first confirmed that As4.1 cells expressed functional Cx molecules. Based on the previous reports and availability of antibodies [35], we immunostained As4.1 cells with anti-Cx43 and anti-Cx45 antibodies. As shown Figure 1A, there was positive punctate staining of $\mathrm{C} \times 43$ and $\mathrm{C} x 45$ around the perinuclear and cell-to-cell contact regions. Consistent with the membrane localization of Cxs, As4.1 cells were well coupled with functional GJs. Injection of fluorescent dye lucifer yellow (LY) into single cell led to diffusion of the dye from the injected cell to several neighboring cells (Figure 1B). These results thus indicate that As4.1 cells express functional Cxs.

We and others have previously reported that the removal of extracellular $\mathrm{Ca}^{2+}$ activated hemichannels $[9,27,29-31]$. We therefore tested whether this also occurred in As4.1 cells. Figure 1C-E show that the exposure of As4.1 cells to $\mathrm{Ca}^{2+}$-free medium initiated a rapid exchange of small molecules between the inside and outside of the plasma membrane, as indicated by the influx of LY and efflux of ATP. In the presence of the hemichannel inhibitor heptanol, this exchange was almost completely blocked. These results indicate that $\mathrm{Ca}^{2+}$ deprivation activates hemichannels in As4.1 cells. 
A
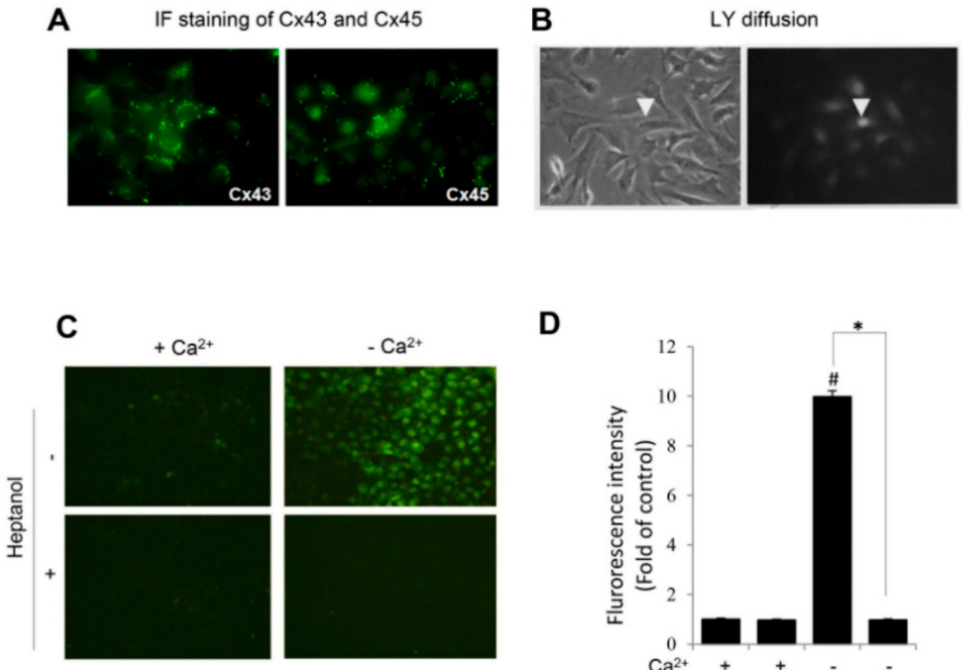

D

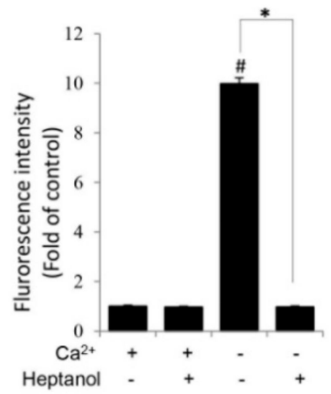

E

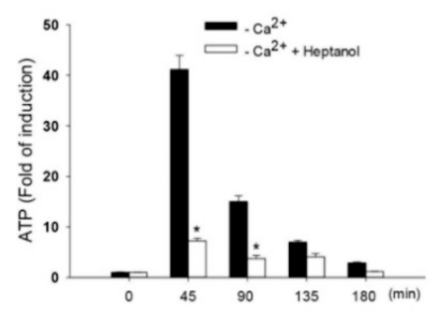

Figure 1. Induction of hemichannel opening by removal of extracellular $\mathrm{Ca}^{2+}$. (A) Immunofluorescent staining of Cx43 and Cx45 in As4.1 cells. As4.1 cells were stained for expression of Cx43 and Cx45. Note the localization of Cx43 and Cx45 in both membrane and cytoplasm. Magnification, X320. (B) Diffusion of LY following single cell injection. LY was injected into single As4.1 cell (arrow head) and the diffusion of LY from the injected cell to neighboring cells was photographed (right image). Magnification, X320. (C,D) Effects of extracellular $\mathrm{Ca}^{2+}$ depletion on hemichannels activities. (C) Effects of $\mathrm{Ca}^{2+}$ depletion on cellular uptake of LY. As4.1 cells were pretreated with or without $3 \mathrm{mM}$ heptanol for $15 \mathrm{~min}$. After that, they were exposed to either normal or $\mathrm{Ca}^{2+}$-free culture medium that contained $0.05 \% \mathrm{LY}$ in the presence of the same concentrations of heptanol for an additional $20 \mathrm{~min}$. The influx of LY was photographed (Magnification, X200). The fluorescent intensity of the cells in C was measured with ImageJ and expressed as relative unit against control (mean $\pm \mathrm{SE}, n=20$; ${ }^{*} p<0.01$ versus control, ${ }^{*} p<0.01$ ). Data shown areone representative result out of four separate experiments. (E) $\mathrm{Ca}^{2+}$ depletion on extracellular release of ATP. As4.1 cells were exposed to $\mathrm{Ca}^{2+}$-free culture medium in the presence or absence of $3 \mathrm{mM}$ heptanol for the indicated time intervals. Cell supernatants were collected and quantitated for ATP concentration. Results are expressed as fold induction relative to control (mean $\pm \mathrm{SE}, n=4)$ ) ${ }^{*} p<0.01$ versus- $\mathrm{Ca}^{2+}$ control.

\subsection{Hemichannels Mediate Low $\mathrm{Ca}^{2+}$-Triggered Activation of cAMP Signaling Pathway}

To determine the role of hemichannels in $\mathrm{Ca}^{2+}$ deprivation-induced renin production, we first examined the influence of hemichannels on renin-regulating cAMP pathway [2,9,11]. Figure 2A shows that the removal of extracellular $\mathrm{Ca}^{2+}$ elevated vasodilator-stimulated phosphoprotein (VASP) and cAMP response element binding protein (CREB) phosphorylation, two validated substrates of cAMP-dependent protein kinase A (PKA) [9,36]. This effect was rapid, being observable as early as $5 \mathrm{~min}$ and lasted for at least $120 \mathrm{~min}$. Intriguingly, in the presence of heptanol, the elevation of phosphorylated VASP and CREB was markedly suppressed. This suppression was more pronounced 
at the later time points. Heptanol almost completely abolished CREB phosphorylation at $30 \mathrm{~min}$ (Figure 2A,B).

A

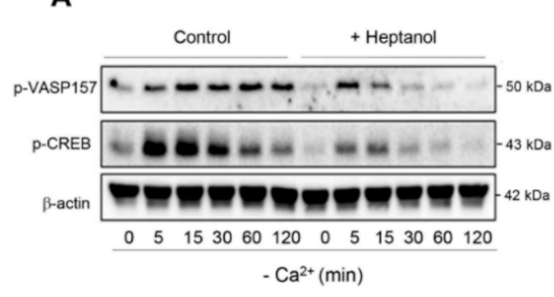

C
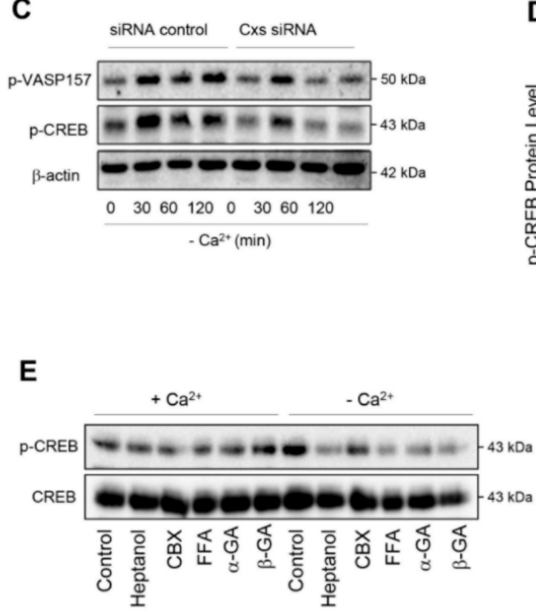

$B$

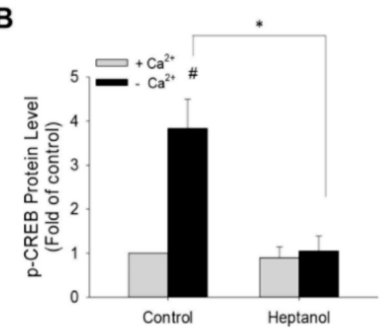

D

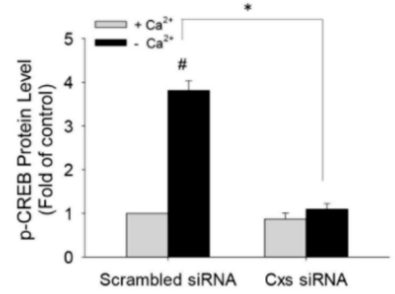

Figure 2. Effects of dysfunction of hemichannels on low $\mathrm{Ca}^{2+}$-induced activation of cAMP signaling pathway. (A) Effect of hemichannel inhibitor heptanol on PKA activation. As4.1 cells were pretreated with or without $3 \mathrm{mM}$ heptanol for $30 \mathrm{~min}$, then exposed to $\mathrm{Ca}^{2+}$-free medium in the presence or absence of heptanol for the indicated time intervals. Cellular proteins were extracted and subjected to Western blot analysis for the phosphorylated levels of VASP and CREB. $\beta$-actin was used as a loading control. (B) Desitometric quantitation of the phosphorylated level of CREB. The intensities of p-CREB signal at the time point of $30 \mathrm{~min}$ were measured using the Scion Image software. The data are expressed as relative intensity of the band against the control (mean $\pm \mathrm{SE}, n=4)$. ${ }^{\#} p<0.01$ versus normal $\mathrm{Ca}^{2+}$ control; ${ }^{*} p<0.01$ versus heptanol-treated cells. (C) Effect of siRNA treatment on cAMP signaling pathway. As4.1 cells were treated with siRNA control or siRNA cocktail targeting against Cxs37, 40, 43 and 45 for $24 \mathrm{~h}$ and exposed to $\mathrm{Ca}^{2+}$-free medium for the indicated times. The levels of phosphorylated VASP157 and phosphorylated CREB were evaluated by Western blot analysis. (D) Densitometric quantitation of the phosphorylated level of CREB at $30 \mathrm{~min}$ point shown in C. The data are expressed as relative intensity of the band against the control (mean $\pm \mathrm{SE}, n=3$ ). ${ }^{\#} p<0.01$ versus normal $\mathrm{Ca}^{2+}$ control; ${ }^{*} p<0.01$ vs. siRNA-treated cells. (E) Effect of various gap junction inhibitors on low $\mathrm{Ca}^{2+}$-induced CREB phosphorylation. As4.1 cells were treated with $3 \mathrm{mM}$ heptanol, $100 \mu \mathrm{M} \mathrm{CBX}$, $50 \mu \mathrm{M}$ FFA, $10 \mu \mathrm{M} \alpha$-or $\beta$-GA in the way same as $\mathrm{A}$ and analyzed for the phosphorylated and total level of CREB.

To confirm that the blocking effect of heptanol was due to its action on the Cx-forming channel, we have downregulated Cxs using siRNA cocktail targeting against Cx37, Cx40, Cx43 and Cx45, which are reported to be expressed in As4.1 cells [35]. Figure 2C,D show that siRNA treatment prevented the phosphorylation of PKA substrates, VASP and CREB, in a way similar to heptanol. In addition, besides heptanol, other hemichannel inhibitors, such as CBX, FFA, $\alpha$ and $\beta$-GA also effectively inhibited low-Ca ${ }^{2+}$-initiated CREB phosphorylation (Figure 2E). These results indicate that Cx-forming hemichannels contribute to the low $\mathrm{Ca}^{2+}$-elicited activation of the cAMP pathway. 


\subsection{Low $\mathrm{Ca}^{2+}$-Induced Activation of cAMP Signaling is Mediated by Adenylyl Cyclase}

Several reports described that low $\mathrm{Ca}^{2+}$-induced renin secretion was mediated by $\mathrm{Ca}^{2+}$-inhibitable adenylyl cyclase $[1,2]$. We therefore tested its involvement under our experimental settings. As shown in Figure 3A, the induction of CREB phosphorylation following the removal of $\mathrm{Ca}^{2+}$ was blocked by adenylyl cyclase inhibitor SQ 22536 in a concentration-dependent manner. A high concentration of SQ 22536 completely abolished the phosphorylation of CREB (Figure 3B,C).

\section{A}

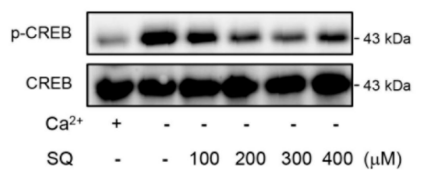

B

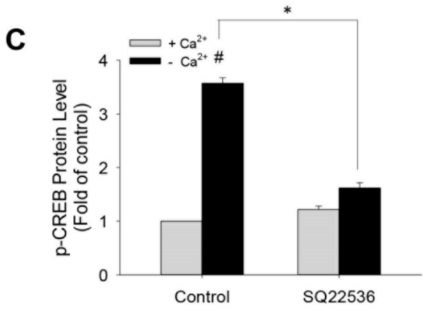

D

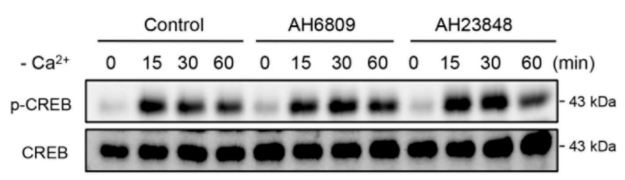

Figure 3. Effects of adenylyl cyclase inhibitor and prostaglandin receptor blockers on low $\mathrm{Ca}^{2+}$-induced CREB phosphorylation. (A,B) Suppression of CREB phosphorylation by adenylyl cyclase inhibitor. As4.1 cells were pretreated with the indicated concentrations of SQ 22536 (A) or $300 \mu \mathrm{M} \mathrm{SQ} 22536$ (B) for $30 \mathrm{~min}$, then exposed to $\mathrm{Ca}^{2+}$-free medium for an additional $15 \mathrm{~min}$. Cellular proteins were extracted and subjected to Western blot analysis for phosphorylated and total level of CREB. (C) Densitometric quantitation of the phosphorylated level of CREB in B. The data are expressed as relative intensity of the band against the control (mean $\pm \mathrm{SE}, n=4$ ). ${ }^{\#} p<0.01$ versus normal $\mathrm{Ca}^{2+}$ control; ${ }^{*} p<0.01$ versus SQ 22536-treated cells. (D) Effect of EP2 and EP4 blockers on CREB phosphorylation. As4.1 cells were pretreated with or without $20 \mu \mathrm{M}$ EP2 inhibitor AH6809 or EP4 inhibitor AH23848 for 30 min, then exposed to $\mathrm{Ca}^{2+}$-free medium for the indicated time intervals. Cellular proteins were extracted and subjected to Western blot analysis for phosphorylated and total level of CREB.

As hemichannel-derived PGE $_{2}$ activates adenylyl cyclase $[10,24,37]$, we hence examined the potential role of $\mathrm{PGE}_{2}$. To this end, we have blocked the receptors that mediate cAMP-elevating effect of $\mathrm{PGE}_{2}$ [10,37]. Figure 3D shows that blockade of EP2 and EP4 with AH6809 and AH23848 failed to affect CREB phosphorylation. These observations indicate that low $\mathrm{Ca}^{2+}$ activates adenylyl cyclase through the $\mathrm{PGE}_{2}$-independent signaling mechanism.

\subsection{Hemichannels Contribute to Low $\mathrm{Ca}^{2+}$-Elicited Expression of Renin}

cAMP is the major second messenger involved in the control of renin production $[9,11,38]$. In this study, we observed that the activation of the cAMP pathway in As4.1 cells with adenyl cyclase activator forskolin resulted in a time-dependent elevation in renin protein level at the $\mathrm{MW}$ of $50 \mathrm{kDa}$ (Figure 4A). Intriguingly, removing extracellular $\mathrm{Ca}^{2+}$ also achieved the same effect (Figure 4B). Furthermore, consistent with the mediating role of hemichannels on cAMP activation, inhibition of hemichannels with heptanol or siRNA significantly blunted the elevation (Figure 4B-F). In addition, the inhibition of 
adenylyl cyclase with SQ 22536 also abolished the elevation (Figure 4G). Collectively, these results indicate that hemichannels contribute to low $\mathrm{Ca}^{2+}$-elicited renin production through its action on the cAMP signaling pathway.

A

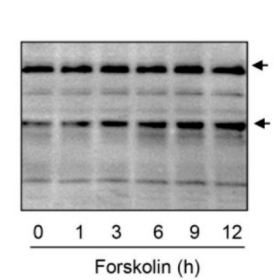

B

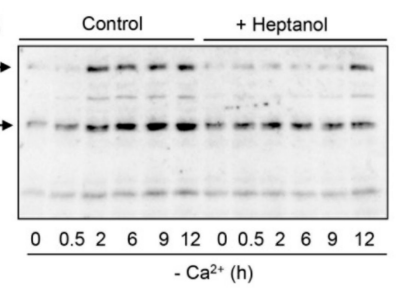

C

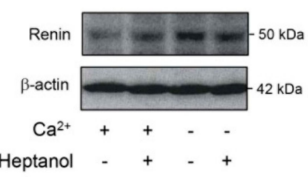

D

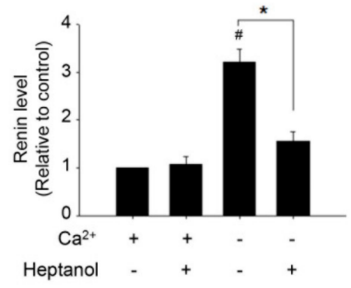

E

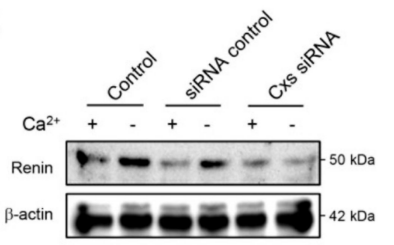

$\mathbf{F}$

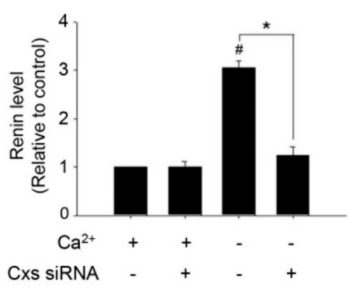

G

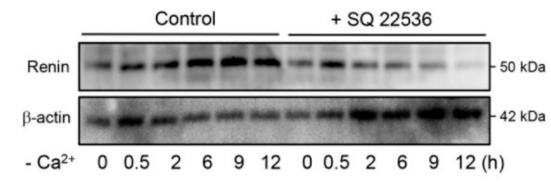

Figure 4. Effects of dysfunction of hemichannels on renin protein levels. (A) Induction of renin production by adenyl cyclase activator forskolin. (B-D). Effect of hemichannel inhibitor heptanol on renin protein levels. As4.1 cells were pretreated with $3 \mathrm{mM}$ heptanol for $30 \mathrm{~min}$, then treated with $\mathrm{Ca}^{2+}$-free medium with or without the same amount of heptanol for the indicated times (B) or $12 \mathrm{~h}(\mathbf{C})$. Cellular proteins were examined by Western blot with an anti-renin antibody. (D) The densitometric quantitation of the intensities of renin signal in $(C)$. The data are expressed as relative intensity of the band against the control (mean $\pm \mathrm{SE}, n=4$ ). ${ }^{\#} p<0.01$ versus normal $\mathrm{Ca}^{2+}$ control; $^{*} p<0.01$ versus heptanol-treated cells. (E) Downregulation of Cxs with siRNA on renin protein levels. As4.1 cells were transfected with siRNA control or SiRNA cocktail targeting against Cx37, 40, 43 and 45 for $24 \mathrm{~h}$, and then exposed to $\mathrm{Ca}^{2+}$-free medium for an additional $12 \mathrm{~h}$. Cellular protein was extracted and subjected to Western blot analysis for renin. Expression of $\beta$-actin is shown as a loading control. (F) Densitometric quantitation of renin levels in $\mathrm{D}$. The data are expressed as relative intensity of the band against the control (mean $\pm \mathrm{SE}, n=3$ ). ${ }^{*} p<0.01$ versus normal $\mathrm{Ca}^{2+}$ control; ${ }^{*} p<0.01$ versus siRNA-treated cells. (G) Influence of blockade of adenylyl cyclase on renin protein levels. As4.1 cells were pretreated with $300 \mu \mathrm{M}$ adenylyl cyclase inhibitor SQ 22536 for $30 \mathrm{~min}$, then treated with $\mathrm{Ca}^{2+}$-free medium with or without the same amount of SQ 22536 for the indicated times intervals. Cellular proteins were subjected to Western blot analysis for renin.

\subsection{Hemichannels Mediate Low $\mathrm{Ca}^{2+}$-Elicited Activation of cAMP Signaling Pathway in Rat Renal Tubular Epithelial Cell NRK}

We also tested whether the hemichannel-mediated activation of the cAMP signaling pathway could also occur in other cell types. For this purpose, we have used a rat renal tubular epithelial 
cell line NRK-52E, which was developed from an epithelioid clone of mixed culture of normal rat kidney cells. In our previous study, we have demonstrated that $\mathrm{Cx} 43$ was the predominant connexin in NRK cells and that the deprivation of extracellular $\mathrm{Ca}^{2+}$ also activated hemichannels in NRK cells [29-31,39]. In consistence with the findings in renin-secreting cells, $\mathrm{Ca}^{2+}$ deprivation also activated the cAMP signaling pathway in NRK, as evidenced by the elevated phosphorylation of VASP and CREB (Figure 5A). This elevation was mediated by Cx43 hemichannels. The inhibition of hemichannels with heptanol or downregulation of Cx43 with siRNA significantly blunted VASP phosphorylation (Figure 5B-E). These results indicate that the hemichannel-mediated activation of the cAMP signaling pathway is not cell type-specific.

A

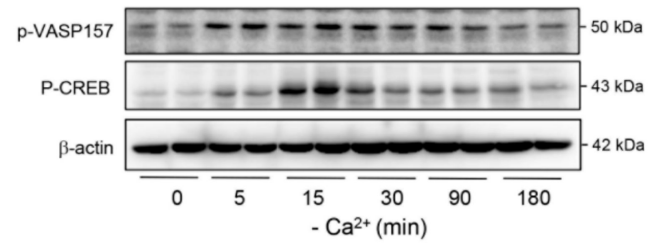

B

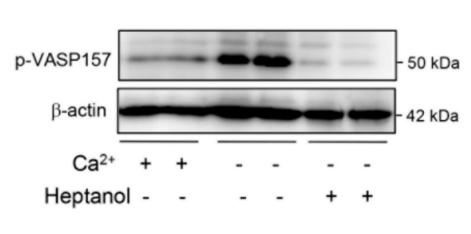

D

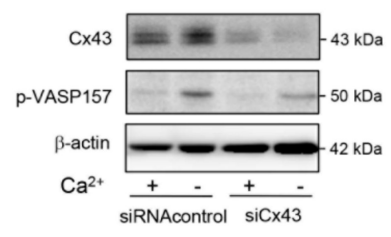

C

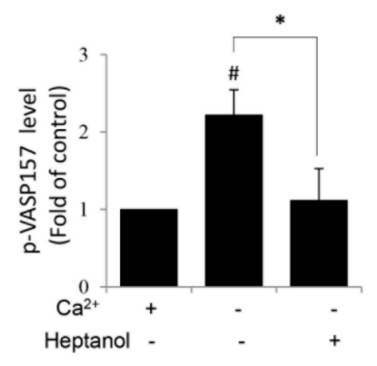

E

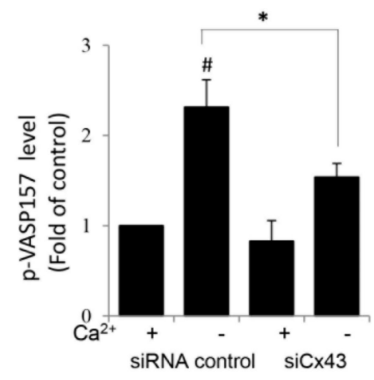

Figure 5. Hemichannel-mediated activation of cAMP signaling pathway in renal tubular epithelial NRK cells. (A) Induction of VASP and CREB phosphorylation by $\mathrm{Ca}^{2+}$ deprivation in NRK cells. NRK cells were exposed to $\mathrm{Ca}^{2}{ }^{+}$-free medium for the indicated time intervals. Cellular proteins were extracted and subjected to Western blot analysis for phosphorylated level of VASP and CREB. $\beta$-actin was used as a loading control. (B-E) Effect of hemichannel inhibitor heptanol $(\mathbf{B}, \mathbf{C})$ and $\mathrm{C} \times 43$ siRNA treatment (D,E) on PKA activation. NRK cells were pretreated with $3 \mathrm{mM}$ heptanol for $30 \mathrm{~min}$ (B) or Cx43 siRNA for $48 \mathrm{~h}$ (D) before exposing to $\mathrm{Ca}^{2+}$-free medium for $10 \mathrm{~min}$. Cellular proteins were extracted and subjected to Western blot analysis for phosphorylated level of VASP and $\beta$-actin. (C,E) Densitometric quantitation of the phosphorylated level of VASP in B and D, respectively. The intensities of p-VASP signal were measured by using the Scion Image software. The data are expressed as relative intensity of the band against the control (mean $\pm \mathrm{SE}, n=4$ ). ${ }^{\#} p<0.05$ versus normal $\mathrm{Ca}^{2+}$ control; ${ }^{*} p<0.05$ versus heptanol or siRNA-treated cells. 


\section{Discussion}

Using a well-characterized mouse renin-secreting cell line As4.1 cells, we characterized activation of $\mathrm{Cx}$ hemichannels as a key molecular event implicated in the low $\mathrm{Ca}^{2+}$-induced activation of the cAMP pathway and the induction of renin. Given the importance of both cAMP signaling and hemichannels in the control of many cellular responses, our finding could have important implications.

cAMP pathway is a well-characterized signaling mechanism for the stimulation of renin synthesis and secretion $[6,8,9,40]$. The pathway starts from the activation of adenylyl cyclase that catalyzes the conversion of ATP into cAMP. The accumulated cAMP activates PKA, which phosphorylates several proteins and regulates a wide spectrum of cell behaviors. It has been reported that elevated cAMP stimulates renin gene expression in JG cells by phosphorylation of CREB through PKA [9,11]. Consistent with these reports, the elevation in renin in this study was preceded by CREB phosphorylation. The prevention of CREB phosphorylation by the inhibition of adenylyl cyclase blunted renin elevation. These observations support the notion that low $\mathrm{Ca}^{2+}$ stimulates renin through the cAMP signaling pathway $[6,8,9,40]$.

One of the intriguing findings in this study is that dysfunction of hemichannels completely blunted the $\mathrm{Ca}^{2+}$ deprivation-induced activation of the cAMP signaling pathway. Activation of hemichannels by removing extracellular $\mathrm{Ca}^{2+}$ has been previously demonstrated at both structural and functional levels. Using an atomic force microscope, Muller et al. observed that lowing extracellular $\mathrm{Ca}^{2+}$ increased outer hemichannel pore diameter [9]. Consistently, many investigators observed increased hemichannel permeability $[22,23,27,29-31]$. In agreement with these reports, we detected a rapid exchange of small molecules between the inside and the outside of the cell membrane following the elimination of extracellular $\mathrm{Ca}^{2+}$ in As4.1 cells. Disruption of the exchange abolished the activation of the cAMP pathway. Our results thus pointed to a critical role of hemichannels in cell responses to low $\mathrm{Ca}^{2+}$ stimulation.

The question naturally occurs as to how hemichannels regulated the cAMP signaling pathway. Consistent with previous reports $[1,2,8]$, the low $\mathrm{Ca}^{2+}$-induced activation of the cAMP pathway in As4.1 cells was mediated by adenylyl cyclase. Inhibition of adenylyl cyclase with SQ22536 completely prevented CREB phosphorylation. In this context, it was conceivable that hemichannels might affect the cAMP pathway through the modulation of adenylyl cyclase activities. Indeed, several hemichannel-derived mediators, such as PGE2 and ATP, have been reported to be able to activate adenylyl cyclase $[10,11,37,41,42]$. However, our data failed to support an involvement of PGE2 because blockade of the relevant $\mathrm{PGE}_{2}$ receptors did not affect CREB phosphorylation. As for the role of ATP on the activation of the cAMP pathway, there are also conflicting reports. A recent study by Iwamoto, et al. demonstrated that efflux of ATP through pannexin hemichannel caused a reduction in intracellular cAMP [43]. Furthermore, ATP is known to induce intra- and inter-cellular $\mathrm{Ca}^{2+}$ signaling, which might negatively affect the cAMP pathway and renin production [7]. Therefore, the mechanisms by which hemichannels regulated cAMP pathway remain to be clarified. Of note, hemichannels might affect cAMP signaling pathway through channel-mediated intra- and extra-cellular exchange of ions, such as $\mathrm{Ca}^{2+}$, chloride and the uncharacterized cations as well. Implication of these ions in the regulation of renin has been previously described $[8,33]$. This speculation also needs to be tested in the future.

By using RT-PCR, Ryan, et al. found that As4.1 cells express several isoforms of Cx molecules, including Cx37, Cx40, Cx43 and Cx45 [35]. Consistently, we confirmed the presence of Cx43 and Cx45 in As4.1 cells at protein level by IF staining and Western blot analysis. In addition, we also detected a positive band of Cx40 in Western blot analysis (data not shown). To completely block hemichannels, we have used siRNA targeting against all reported Cxs, including Cx37, 40, 43 and 45. This strategy achieved a suppressive effect comparable to heptanol on cAMP activation and renin production. At present, the role of distinct $\mathrm{Cx}$ molecule in mediating hemichannel activity and activating cAMP pathway in renin-secreting cells is unclear. Our preliminary experiment using siRNA against individual $C x$ revealed that downregulation of $C \times 43$ alone appeared to be enough to influence CREB phosphorylation (Supplementary Figure S1). As a predominant Cx expressed in 
many cell types, Cx43-forming hemichannels might play a major role in channel permeability in As4.1 cells. Further characterization of $\mathrm{Cx}$ molecules involved in the control of hemichannel activity and the cAMP pathway in the renin-secreting juxtaglomerular cells, using strategies such as specific siRNA or connexin mimetic peptide, may lead to the development of more effective approaches in the control of renin secretion in vivo.

Of note, other than its action on Cx channels, heptanol used in this study also has other biological effects. Given that the effects achieved by heptanol were similarly obtained by siRNAs and several structurally different $C x$ channel inhibitors, it is conceivable that the observed effects were most likely due to its action on Cx channels.

Apart from elimination of intra- or extra-cellular $\mathrm{Ca}^{2+}$, hemichannels are also activated by $\mathrm{Cx}$ mutations, depolarization of the membrane potential, mechanic strain, and hypoxia, as well as by changes of cellular redox status $[16,22,44]$. It is presently unclear whether hemichannel opening initiated by other activators also similarly affects the cAMP signaling pathway. More detailed investigation in this direction may be needed in the future.

It is also interesting to mention that $\mathrm{Cx}$ hemichannels are reported to be activated by cAMP itself and cAMP-elevating agents, such as nitric oxide [45-48], the participation of hemichannels in mediating the activation of the CAMP signaling pathway suggests that there may exist a positive reciprocal regulatory loop between Cxs and cAMP in the amplification and sustainment of the cAMP signaling pathway. This idea also needs testing in the future studies.

In the last several years, great attention has been paid on the role of GJs in the control of renin. Several lines of evidences indicate that coupling through Cx40 channels is required for regulative mechanisms of renin expression and secretion as well as the correct localization of renin-expressing cells. Disruption of Cx40-mediated intercellular signaling leads to loss of pressure control of renin secretion and development of hypertension $[19,21,49,50]$. Our current findings suggest that Cxs might regulate renin through multiple mechanisms and toward the opposite direction. Depending on the context, Cx-forming channels might also contribute to renin synthesis and secretion. Apart from the stimulation of renin synthesis and secretion, cAMP-signaling pathway also participates in the regulation of a wide spectrum of cell processes, including cell migration, constriction, proliferation and differentiation. It is conceivable that hemichannels might be implicated in many pathophysiological situations and serve as potential targets for therapeutic intervention. Future studies will be focused on unraveling the underlying mechanisms behind this regulatory effect of hemichannels. Progress in this direction may provide further insight into gap junction physiology in the cardiovascular system and other organ systems as well.

In summary, our study characterizes hemichannel opening as an indispensable event for the $\mathrm{Ca}^{2+}$-elicited activation of the cAMP signaling pathway in renin-secreting cells. Our finding thus provides novel mechanistic insights into the regulatory effects of low $\mathrm{Ca}^{2+}$ on renin production and highlights the potential importance of $\mathrm{Cx}$ hemichannels in the cardiovascular system.

\section{Materials and Methods}

\subsection{Reagents}

Anti-Cx45 was from Santa Cruz (\#sc-374354, Santa Cruz, CA, USA). Anti-phospho-cAMP response element-binding protein (CREB; Ser133; \#11052) and anti-CREB (\#21052-2) were purchased from Signalway Antibody (Pearland, TX, USA). Anti-phospho-vasodilator-stimulated phosphoprotein (anti-p-VASP, Ser157; \#AB3839) and anti-Cx40 antibody (\#AB1726) were obtained from Calbiochem (Darmstadt, Germany). Anti-renin antibody was bought from AnaSpec (\#54371; San Jose, CA, USA) and also gifted by Prof. T lnagami (Department of Biochemistry, Vanderbilt University). FITC-conjugated swine anti-rabbit immunoglobulin (\#F0205) was purchased from DAKO (Glostoup, Denmark). Anti-Cx43 (\#C6219), anti- $\beta$-actin (\#A3854), heptanol, lucifer yellow (LY), trypsin and all other chemicals were obtained from Sigma-Aldrich Japan (Tokyo, Japan). 


\subsection{Cell Culture}

The renin-expressing As4.1 cell line was obtained from the American Type Culture Collection (ATCC No. CRL2193). For maintenance and passage, cells were cultured at $37^{\circ} \mathrm{C}$ in RPMI- 1640 with L-glutamine, phenol red and HEPES medium (Wako, Tokyo, Japan) supplemented with $5 \%$ fetal bovine serum (FBS). For comparison of cell responses between normal $\mathrm{Ca}^{2+}$ and $\mathrm{Ca}^{2+}$-free situations, cells were exposed to $\mathrm{Ca}^{2+}$-free DMEM (Gibco-BRL, Catalogue number \#21068) with or without supplementation of $1.8 \mathrm{mM} \mathrm{Ca}^{2+}$.

\subsection{Immunocytochemical Analysis}

Immunocytochemical staining for $\mathrm{Cx} 40,43$ and 45 was performed as previously reported [7,29]. In brief, cultured As4.1 cells were fixed in $2 \%$ paraformaldehyde, permeabilized with $1 \%$ Triton X-100, and incubated overnight with anti-Cx40, Cx43 and Cx45 antibody (diluted 1:100 in 1\% FBS in PBS; $4{ }^{\circ} \mathrm{C}$ ). After rinsing with PBS, the appropriate secondary antibody was added for $2 \mathrm{~h}$ at room temperature. The chamber slides were covered with Tris-buffered moviol ( $\mathrm{pH}$ 8.6), and microscopy was performed with an Olympus BX50 microscope with a $40 \times$ Planapo and $570 \mathrm{~nm}$ emission filter. Immuofluorescent images were captured using a CCD camera attached to the microscope.

\subsection{Evaluation of GJIC by Microinjection of LY}

GJIC was assessed by transfer of the membrane-impermeable fluorescent dye, LY after single cell microinjection using an automated microinjection system (Zeiss Oberkochen, Jena, Germany), as described previously [7].

\subsection{Dye Uptake Assay}

Hemichannel permeability was evaluated by the cellular uptake of LY as described previously [22, 29-31]. As4.1 cells were exposed to $\mathrm{Ca}^{2+}$-free medium in the presence or absence of $0.05 \% \mathrm{LY}$ for $20 \mathrm{~min}$. The cells were then rinsed and fixed with $3 \%$ paraformaldehyde. Immunofluorescent images were captured using a CCD camera attached to an Olympus IX71 microscope (Tokyo, Japan).

\subsection{ATP Measurement}

ATP was measured using a luciferin/luciferase bioluminescence assay kit (Molecular Probes). The intensity of chemiluminescent signal was determined by a luminometer (Gene Light 55; Microtech Nition, Chiba, Japan) as described previously [7,22,23,29-31].

\subsection{Western Blot Analysis}

Western blot was performed using an enhanced chemiluminescence system [22,23,29-31]. Briefly, equal amounts of extracted cellular proteins were separated by $10 \%$ SDS-polyacrylamide gels and electrotransferred onto polyvinylidene difluoride membranes. After blocking with $3 \%$ BSA in PBS, the membranes were incubated with primary antibody. After washing with PBS-0.1\% Tween 20, filters were probed with horseradish peroxidase-conjugated sheep anti-rabbit IgG or rabbit anti-mouse IgG (Cell Signaling; Beverly, MA, USA). Immunoreactivity was detected by an enhanced chemiluminescence system (Amersham Biosciences, Buckinghamshire, UK). The chemiluminescent signal was captured with a Fujifilm luminescent image LAS-4000 analyzer (Fujifilm, Tokyo, Japan). Densitometric quantitation of the blots was performed using the Scion Image software (Scion Corporation).

\subsection{Transient Transfection of As4.1 Cells with siRNA}

Cells were transiently transfected with siRNA specifically targeting against Cx37 (Mm_Gja4_1 FlexiTube siRNA), Cx40 (Mm_Gja5_1 FlexiTube siRNA), Cx43 (Mm_Gja 1_2 HP siRNA) and Cx45 (Mm_Gja7_2 FlexiTube siRNA, Qiagen, Japan) or a negative control siRNA (AllStars Negative

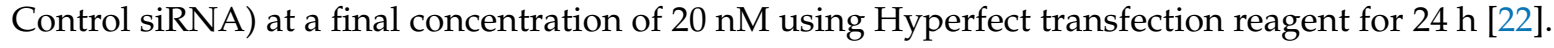


After transfection, cells were left untreated or exposed to $\mathrm{Ca}^{2+}$-free medium for the indicated time. Cellular protein was extracted and subjected to western blot analysis of the targeted proteins.

\subsection{Statistical Analysis}

Values are expressed as mean \pm SE. Comparison of two populations was performed using a Student's $t$-test. The analysis was performed using SigmaStat statistical software (Jandel Scientific, CA, USA). $p<0.05$ was considered to be a statistically significant difference.

Supplementary Materials: The following are available online at http://www.mdpi.com/1422-0067/21/12/4462/s1, Figure S1: Effects of treatment of As4.1 cells with siRNA against distinct $\mathrm{Cx}$ molecule on $\mathrm{Ca}^{2+}$ deprivation-induced phosphorylation of CREB. As4.1 cells were treated with the indicated siRNA against Cx37, 40, 43 and 45 for $24 \mathrm{~h}$. After that, they were exposed to $\mathrm{Ca}^{2+}$-free medium for $30 \mathrm{~min}$. Cellular protein was extracted and subjected to Western blot analysis for the effectiveness of $\mathrm{Cx} 43$ siRNA in downregulation of $\mathrm{Cx} 43$ protein level (A) and phosphorylated CREB (B). Note the elevation of p-CREB following removal of extracellular $\mathrm{Ca}^{2+}$ and its suppression by Cx43 siRNA.

Author Contributions: J.H. performed research, analyzed the data and wrote the manuscript; J.Y. designed the study and wrote the manuscript. All authors have read and agreed to the published version of the manuscript.

Funding: This work was supported by Grants-in-Aid for Scientific Research from the Ministry of Education, Culture, Sports, Science and Technology, Japan (grant numbers 20K08606 to JY).

Acknowledgments: We thank T lnagami, Department of Biochemistry, Vanderbilt University for providing us the anti-renin antibody.

Conflicts of Interest: The authors declare no conflicts of interest.

\section{Abbreviations}

ATP adenosine triphosphate

$\mathrm{Ca}^{2+}$ calcium

CREB cAMP response element binding protein

Cx connexin

GJ gap junction

JG juxtaglomerular

$\mathrm{NAD}^{+}$nicotinamide adenine dinucleotide

NRK normal rat kidney

PGE2 prostaglandin E2

PKA protein kinase $\mathrm{A}$

LY lucifer yellow

VASP vasodilator-stimulated phosphoprotein

\section{References}

1. Ortiz-Capisano, M.C.; Ortiz, P.A.; Harding, P.; Garvin, J.L.; Beierwaltes, W.H. Adenylyl cyclase isoform v mediates renin release from juxtaglomerular cells. Hypertension 2007, 49, 618-624. [CrossRef] [PubMed]

2. Ortiz-Capisano, M.C.; Ortiz, P.A.; Harding, P.; Garvin, J.L.; Beierwaltes, W.H. Decreased intracellular calcium stimulates renin release via calcium-inhibitable adenylyl cyclase. Hypertension 2007, 49, 162-169. [CrossRef] [PubMed]

3. Atchison, D.K.; Ortiz-Capisano, M.C.; Beierwaltes, W.H. Acute activation of the calcium-sensing receptor inhibits plasma renin activity in vivo. Am. J. Physiol. Regul. Integr. Comp. Physiol. 2010, 299, R1020-R1026. [CrossRef]

4. Klar, J.; Sigl, M.; Obermayer, B.; Schweda, F.; Kramer, B.K.; Kurtz, A. Calcium inhibits renin gene expression by transcriptional and posttranscriptional mechanisms. Hypertension 2005, 46, 1340-1346. [CrossRef]

5. Grunberger, C.; Obermayer, B.; Klar, J.; Kurtz, A.; Schweda, F. The calcium paradoxon of renin release: Calcium suppresses renin exocytosis by inhibition of calcium-dependent adenylate cyclases AC5 and AC6. Circ. Res. 2006, 99, 1197-1206. [CrossRef]

6. Schweda, F.; Kurtz, A. Cellular mechanism of renin release. Acta Physiol. Scand. 2004, 181, 383-390. [CrossRef] [PubMed] 
7. Yao, J.; Suwa, M.; Li, B.; Kawamura, K.; Morioka, T.; Oite, T. ATP-dependent mechanism for coordination of intercellular $\mathrm{Ca}^{2+}$ signaling and renin secretion in rat juxtaglomerular cells. Circ. Res. 2003, 93, 338-345. [CrossRef]

8. Beierwaltes, W.H. The role of calcium in the regulation of renin secretion. Am. J. Physiol. Ren. Physiol. 2010, 298, F1-F11. [CrossRef]

9. Klar, J.; Sandner, P.; Muller, M.W.; Kurtz, A. Cyclic AMP stimulates renin gene transcription in juxtaglomerular cells. Pflug. Arch. 2002, 444, 335-344. [CrossRef]

10. Schweda, F.; Klar, J.; Narumiya, S.; Nusing, R.M.; Kurtz, A. Stimulation of renin release by prostaglandin E2 is mediated by EP2 and EP4 receptors in mouse kidneys. Am. J. Physiol. Ren. Physiol. 2004, 287, F427-F433. [CrossRef]

11. Gonzalez, A.A.; Salinas-Parra, N.; Leach, D.; Navar, L.G.; Prieto, M.C. PGE2 upregulates renin through E-prostanoid receptor 1 via PKC/cAMP/CREB pathway in M-1 cells. Am. J. Physiol. Ren. Physiol. 2017, 313, F1038-F1049. [CrossRef] [PubMed]

12. Ackermann, M.; Ritthaler, T.; Riegger, G.; Kurtz, A.; Kramer, B.K. Endothelin inhibits cAMP-induced renin release from isolated renal juxtaglomerular cells. J. Cardiovasc. Pharm. 1995, 26, S135-S137. [CrossRef]

13. Lu, M.; Liu, Y.H.; Goh, H.S.; Wang, J.J.; Yong, Q.C.; Wang, R.; Bian, J.S. Hydrogen sulfide inhibits plasma renin activity. J. Am. Soc. Nephrol. 2010, 21, 993-1002. [CrossRef] [PubMed]

14. Yao, J.; Zhu, Y.; Morioka, T.; Oite, T.; Kitamura, M. Pathophysiological roles of gap junction in glomerular mesangial cells. J. Membr. Biol. 2007, 217, 123-130. [CrossRef]

15. Yao, J.; Oite, T.; Kitamura, M. Gap junctional intercellular communication in the juxtaglomerular apparatus. Am. J. Physiol. Ren. Physiol. 2009, 296, F939-F946. [CrossRef]

16. Bennett, M.V.; Contreras, J.E.; Bukauskas, F.F.; Saez, J.C. New roles for astrocytes: Gap junction hemichannels have something to communicate. Trends Neurosci. 2003, 26, 610-617. [CrossRef]

17. Wagner, C. Function of connexins in the renal circulation. Kidney Int. 2008, 73, 547-555. [CrossRef]

18. Peti-Peterdi, J. Calcium wave of tubuloglomerular feedback. Am. J. Physiol. Ren. Physiol. 2006, 291, F473-F480. [CrossRef]

19. Wagner, C.; de Wit, C.; Kurtz, L.; Grunberger, C.; Kurtz, A.; Schweda, F. Connexin40 is essential for the pressure control of renin synthesis and secretion. Circ. Res. 2007, 100, 556-563. [CrossRef]

20. Schweda, F.; Kurtz, L.; de Wit, C.; Janssen-Bienhold, U.; Kurtz, A.; Wagner, C. Substitution of connexin40 with connexin 45 prevents hyperreninemia and attenuates hypertension. Kidney Int. 2009, 75, 482-489. [CrossRef]

21. Lubkemeier, I.; Machura, K.; Kurtz, L.; Neubauer, B.; Dobrowolski, R.; Schweda, F.; Wagner, C.; Willecke, K.; Kurtz, A. The connexin 40 A96S mutation causes renin-dependent hypertension. J. Am. Soc. Nephrol. 2011, 22, 1031-1040. [CrossRef]

22. Fang, X.; Huang, T.; Zhu, Y.; Yan, Q.; Chi, Y.; Jiang, J.X.; Wang, P.; Matsue, H.; Kitamura, M.; Yao, J. Connexin43 hemichannels contribute to cadmium-induced oxidative stress and cell injury. Antioxid. Redox Signal. 2011, 14, 2427-2439. [CrossRef]

23. Li, K.; Chi, Y.; Gao, K.; Yan, Q.; Matsue, H.; Takeda, M.; Kitamura, M.; Yao, J. Connexin43 hemichannel-mediated regulation of connexin43. PLoS ONE 2013, 8, e58057. [CrossRef] [PubMed]

24. Siller-Jackson, A.J.; Burra, S.; Gu, S.; Xia, X.; Bonewald, L.F.; Sprague, E.; Jiang, J.X. Adaptation of connexin 43-hemichannel prostaglandin release to mechanical loading. J. Biol. Chem. 2008, 283, 26374-26382. [CrossRef] [PubMed]

25. Burra, S.; Jiang, J.X. Regulation of cellular function by connexin hemichannels. Int. J. Biochem. Mol. Biol. 2011, 2, 119. [PubMed]

26. Jiang, L.; Foster, F.M.; Ward, P.; Tasevski, V.; Luttrell, B.M.; Conigrave, A.D. Extracellular ATP triggers cyclic AMP-dependent differentiation of HL-60 cells. Biochem. Biophys. Res. Commun. 1997, 232, 626-630. [CrossRef] [PubMed]

27. Stout, C.E.; Costantin, J.L.; Naus, C.C.; Charles, A.C. Intercellular calcium signaling in astrocytes via ATP release through connexin hemichannels. J. Biol. Chem. 2002, 277, 10482-10488. [CrossRef]

28. Stridh, M.H.; Tranberg, M.; Weber, S.G.; Blomstrand, F.; Sandberg, M. Stimulated efflux of amino acids and glutathione from cultured hippocampal slices by omission of extracellular calcium: Likely involvement of connexin hemichannels. J. Biol. Chem. 2008, 283, 10347-10356. [CrossRef] 
29. Chi, Y.; Zhang, X.; Mitsui, T.; Kamiyama, M.; Takeda, M.; Yao, J. Connexin43 hemichannels contributes to the disassembly of cell junctions through modulation of intracellular oxidative status. Redox Biol. 2016, 9, 198-209. [CrossRef]

30. Chi, Y.; Gao, K.; Zhang, H.; Takeda, M.; Yao, J. Suppression of cell membrane permeability by suramin: Involvement of its inhibitory actions on connexin 43 hemichannels. Br. J. Pharm. 2014, 171, 3448-3462. [CrossRef]

31. Chi, Y.; Gao, K.; Li, K.; Nakajima, S.; Kira, S.; Takeda, M.; Yao, J. Purinergic control of AMPK activation by ATP released through connexin 43 hemichannels-pivotal roles in hemichannel-mediated cell injury. J. Cell Sci. 2014, 127, 1487-1499. [CrossRef] [PubMed]

32. Russ, U.; Rauch, U.; Quast, U. Pharmacological evidence for a KATP channel in renin-secreting cells from rat kidney. J. Physiol. 1999, 517, 781-790. [CrossRef] [PubMed]

33. Jensen, B.L.; Skott, O. Renin release from permeabilized juxtaglomerular cells is stimulated by chloride but not by low calcium. Am. J. Physiol. 1994, 266, F604-F611. [CrossRef] [PubMed]

34. Friis, U.G.; Madsen, K.; Svenningsen, P.; Hansen, P.B.; Gulaveerasingam, A.; Jorgensen, F.; Aalkjaer, C.; Skott, O.; Jensen, B.L. Hypotonicity-induced Renin exocytosis from juxtaglomerular cells requires aquaporin-1 and cyclooxygenase-2. J. Am. Soc. Nephrol. 2009, 20, 2154-2161. [CrossRef] [PubMed]

35. Ryan, M.J.; Liu, B.; Herbowy, M.T.; Gross, K.W.; Hajduczok, G. Intercellular communication between renin expressing As4.1 cells, endothelial cells and smooth muscle cells. Life Sci. 2003, 72, 1289-1301. [CrossRef]

36. Halbrugge, M.; Friedrich, C.; Eigenthaler, M.; Schanzenbacher, P.; Walter, U. Stoichiometric and reversible phosphorylation of a $46-\mathrm{kDa}$ protein in human platelets in response to cGMP- and cAMP-elevating vasodilators. J. Biol. Chem. 1990, 265, 3088-3093.

37. Cherian, P.P.; Siller-Jackson, A.J.; Gu, S.; Wang, X.; Bonewald, L.F.; Sprague, E.; Jiang, J.X. Mechanical strain opens connexin 43 hemichannels in osteocytes: A novel mechanism for the release of prostaglandin. Mol. Biol. Cell 2005, 16, 3100-3106. [CrossRef]

38. Pan, L.; Black, T.A.; Shi, Q.; Jones, C.A.; Petrovic, N.; Loudon, J.; Kane, C.; Sigmund, C.D.; Gross, K.W. Critical roles of a cyclic AMP responsive element and an E-box in regulation of mouse renin gene expression. J. Biol. Chem. 2001, 276, 45530-45538. [CrossRef]

39. Yao, J.; Huang, T.; Fang, X.; Chi, Y.; Zhu, Y.; Wan, Y.; Matsue, H.; Kitamura, M. Disruption of gap junctions attenuates aminoglycoside-elicited renal tubular cell injury. Br. J. Pharm. 2010, 160, 2055-2068. [CrossRef]

40. Lu, M.; Liu, Y.H.; Ho, C.Y.; Tiong, C.X.; Bian, J.S. Hydrogen sulfide regulates cAMP homeostasis and renin degranulation in As4.1 and rat renin-rich kidney cells. Am. J. Physiol. Cell Physiol. 2012, 302, C59-C66. [CrossRef]

41. Puceat, M.; Bony, C.; Jaconi, M.; Vassort, G. Specific activation of adenylyl cyclase V by a purinergic agonist. FEBS Lett. 1998, 431, 189-194. [CrossRef]

42. Torres, B.; Zambon, A.C.; Insel, P.A. P2Y11 receptors activate adenylyl cyclase and contribute to nucleotide-promoted cAMP formation in MDCK-D(1) cells. A mechanism for nucleotide-mediated autocrine-paracrine regulation. J. Biol. Chem. 2002, 277, 7761-7765. [CrossRef] [PubMed]

43. Iwamoto, T.; Nakamura, T.; Doyle, A.; Ishikawa, M.; de Vega, S.; Fukumoto, S.; Yamada, Y. Pannexin 3 regulates intracellular ATP/cAMP levels and promotes chondrocyte differentiation. J. Biol. Chem. 2010, 285, 18948-18958. [CrossRef] [PubMed]

44. Anselmi, F.; Hernandez, V.H.; Crispino, G.; Seydel, A.; Ortolano, S.; Roper, S.D.; Kessaris, N.; Richardson, W.; Rickheit, G.; Filippov, M.A.; et al. ATP release through connexin hemichannels and gap junction transfer of second messengers propagate $\mathrm{Ca}^{2+}$ signals across the inner ear. Proc. Natl. Acad. Sci. USA 2008, 105, 18770-18775. [CrossRef]

45. Plotkin, L.I. Connexin 43 hemichannels and intracellular signaling in bone cells. Front. Physiol. 2014, 5, 131. [CrossRef]

46. Mitropoulou, G.; Bruzzone, R. Modulation of perch connexin35 hemi-channels by cyclic AMP requires a protein kinase A phosphorylation site. J. Neurosci. Res. 2003, 72, 147-157. [CrossRef]

47. Retamal, M.A.; Yin, S.; Altenberg, G.A.; Reuss, L. Modulation of Cx46 hemichannels by nitric oxide. Am. J. Physiol. Cell Physiol. 2009, 296, C1356-C1363. [CrossRef] [PubMed]

48. Yao, J.; Hiramatsu, N.; Zhu, Y.; Morioka, T.; Takeda, M.; Oite, T.; Kitamura, M. Nitric oxide-mediated regulation of connexin43 expression and gap junctional intercellular communication in mesangial cells. J. Am. Soc. Nephrol. 2005, 16, 58-67. [CrossRef] 
49. Spray, D.C. Hypertension in connexin40-null mice: A renin disorder. Kidney Int. 2007, 72, 781-782. [CrossRef]

50. Gomez, R.A.; Sequeira Lopez, M.L. Who and where is the renal baroreceptor?: The connexin hypothesis. Kidney Int. 2009, 75, 460-462. [CrossRef]

(c)

(C) 2020 by the authors. Licensee MDPI, Basel, Switzerland. This article is an open access article distributed under the terms and conditions of the Creative Commons Attribution (CC BY) license (http://creativecommons.org/licenses/by/4.0/). 